\title{
AS ADAPTAÇÕES LITERÁRIAS EM QUADRINHOS SELECIONADAS PELO PNBE: SOLUÇÕES E PROBLEMAS \\ NA SALA DE AULA
}

\begin{abstract}
Resumo
Vanessa Yamaguti

Universidade Federal de São Paulo

O Programa Nacional Biblioteca da Escola (PNBE) foi criado em $1997 \mathrm{com}$ o objetivo de democratizar o acesso ao livro e incentivar à leitura. Em 2006, o programa passou a selecionar obras em quadrinhos, o que, segundo Vergueiro e Ramos (2009), é um reflexo do uso de tiras, charges e cartuns em provas, vestibulares e em livros didáticos, e a inserção da necessidade de se trabalhar gêneros não-verbais nos Parâmetros Curriculares Nacionais (PCN). E, para os pesquisadores, há uma preferência nos editais por obras em quadrinhos de adaptações literárias, todavia quais são os benefícios e os malefícios dessa preferência, e principalmente de seleção? É o que nos propomos a discutir e a tentar responder ao longo deste artigo, com enfoque no trabalho em sala de aula.
\end{abstract}

Palavras-chaves: PNBE; Quadrinhos; Adaptações literárias. 


\title{
THE LITERARY ADAPTATIONS IN \\ COMIC BOOKS SELECTED BY PNBE: \\ SOLUTIONS AND PROBLEMS IN \\ CLASSROOM
}

\begin{abstract}
The Programa Nacional Biblioteca da Escola (PNBE) created in 1997, was developed to guarantee the access to books and to stimulate the reading. In 2006, the program started selecting works in comic books, according Vergueiro and Ramos (2009), this inclusion is the reflection of the use of the comic strips, caricatures and cartoons in tests, entrance exams and textbook and the insertion of the necessity to work with non-verbal genres, specifically comics, in Parâmetros Curriculares Nacionais $(\mathrm{PCN})$.And for researchers, there is a preference in bids for comic masterpieces of literary adaptations, but what are the benefits and harms of this preference, and principally of this selection? It is what we propose to discuss in and try to answer throughout this article, focusing on work in the classroom
\end{abstract}

Key words: PNBE; Comic books; Literary adaptations. 


\section{Introdução ${ }^{1}$}

Durante o governo de Fernando Henrique Cardoso foi criado ${ }^{2}$ o PNBE (Programa Nacional Biblioteca da Escola) com o objetivo de democratizar e garantir o acesso ao livro, desta forma incentivar à leitura. A partir de 1998 todos os anos o MEC (Ministério da Educação) compra e distribui obras para as escolas públicas do país que atendam aos requisitos, a) se a escola está cadastrada no censo escolar realizado pelo INEP (Instituto Nacional de Estudos e Pesquisas Educacionais Anísio Teixeira), b) se ela se enquadra no nível atendido ${ }^{3}$ e c) a quantidade de alunos matriculados na escola.

Em 2006, segundo Vergueiro e Ramos (2009), as histórias em quadrinhos são inseridas no programa, destinadas a todos os níveis com seleção em todos os anos desde então. Para os pesquisadores, há uma preferência por quadrinhos de adaptações literárias, transmitindo a ideia de que o governo entende os quadrinhos como facilitadores de leitura da obra adaptada.

Devido a isso, nossa pesquisa buscou verificar quantas e quais foram as obras de HQ (História em Quadrinho) de adaptações literárias selecionadas pelo programa de 2006 a 2012. Também realizou-se uma análise dos dados encontrados, apontando possíveis soluções para o uso dessas obras em sala de aula e quais seriam os problemas a serem enfrentados. Além de discutir sobre as vantagens e desvantagens desta preferência e de seleção.

\section{O PNBE}

De acordo com Fernandes (2007), a partir de programas, congressos, movimentos e campanhas de incentivo à leitura houve um aumento considerável de produção e circulação de obras, transformando o Brasil no $8^{\circ}$ mercado editorial do mundo, sendo o governo federal o

\footnotetext{
${ }^{1}$ Graduada em Letras pela Universidade Federal de São Paulo. Aluna Especial do Programa de PósGraduação em Educação na mesma universidade.

${ }^{2}$ O programa foi criado em 1997.

${ }^{3}$ A cada ano troca-se o nível escolar, em um ano atendem-se os anos iniciais do Ensino Fundamental, Educação Infantil e ao EJA (Educação de Jovens e Adultos), noutro os anos finais do Ensino Fundamental e o Ensino Médio.
}

Olh@res, Guarulhos, v. 2, n. 1, p. 441-459. Maio, 2014. 
principal comprador, por causa das políticas públicas de distribuição de livros didáticos e paradidáticos.

Atualmente, o PNBE, através do FNDE (Fundo Nacional de Desenvolvimento da Educação), é o principal comprador de livros paradidáticos no mercado editorial brasileiro. Segundo Paiva (2012), o programa foi criado em 1997 com o objetivo de democratizar e permitir o acesso às obras de literatura e incentivar à leitura. Destinado às escolas públicas brasileiras de Educação Básica (Educação Infantil, Ensino Fundamental e Médio) e em 2000 foram destinados materiais didático pedagógico ao EJA (Educação de Jovens e Adultos) e desde 2003 são distribuídas obras para este nível de ensino.

Para a pesquisadora, além da compra do acervo se faz necessária uma política pública que viabilize a circulação das obras, visto que, como apontado por Montuani (2012), em pesquisa realizada em Belo Horizonte, na rede municipal de ensino, há escolas em que os funcionários não sabiam sobre a existência do o acervo, casos em que estavam em processo de catalogação e até que estavam em caixas.

Contudo, é necessário ressaltar a importância da distribuição dos acervos devido ao histórico do nosso país em relação ao número de leitores, pois, a partir do PNBE e outras políticas públicas que foram desenvolvidas ao longo dos anos, democratizou-se o acesso ao livro. E, se levarmos em consideração as condições socioeconômicas e o histórico de analfabetismo em nosso país entenderemos sua aplicação. Fernandes (2007) considera não ser possível dissociar o acesso ao livro às condições financeiras do cidadão ao analisar os dados da Câmara Brasileira do Livro de 2001.

As estatísticas indicam que o mercado comprador de livros representa $20 \%$ da população brasileira alfabetizada com 14 anos ou mais (CÂMARA BRASILEIRA DO LIVRO, 2001, p. 20). Dessa pequena parcela de compradores, $60 \%$ têm mais de 30anos, $53 \%$ são moradores da Região Sudeste e mais da metade são de cidades grandes e metrópoles (Ibid., p. 26). Os maiores índices de leitura e compra de livros encontram-se nos estados de renda mais elevada: classe A e com instrução superior. Ou seja, $1 \%$ da população possui $22 \%$ dos livros, revelando que a posse de livros "apresenta dinâmica idêntica à distribuição de renda no país, onde poucos têm muito e muitos têm pouco" (Ibid., p. 36). (FERNANDES: 2007, p. 18-19)

Olh@res, Guarulhos, v. 2, n. 1, p. 441-459. Maio, 2014. 
Desta forma, mesmo com a dificuldade em fazer com que os livros circulem nas escolas e fora dela, o PNBE, no primeiro momento e quando de fato são disponibilizados nas escolas, garante e permite o acesso ao livro, agora são necessárias políticas de formação de leitores e mediadores, visto que, como define Kalman (2004), a disponibilidade não garante o acesso, pois disponibilidade denota a presença física do material, a garantia de infraestrutura, enquanto que acesso refere-se às oportunidades existentes de práticas do uso da língua escrita a partir da leitura ou da escrita.

\section{O processo de seleção}

Segundo Paiva (2012), para a seleção do acervo do programa, o CEALE (Centro de Alfabetização, Leitura e Escrita) da Universidade Federal de Minas Gerais, responsável pela seleção, utiliza os seguintes critérios: qualidade do texto, adequação temática e projeto gráfico. Antes, porém, todos os livros inscritos passam por uma triagem feita pelo Instituto de Pesquisas Tecnológicas (IPT). No próprio CEALE são excluídas as produções que não atendam ao edital: "quanto à estrutura editorial e as especificações técnicas mínimas como formato, capa, miolo, acabamento, além de obras de cunho explicitamente moralizantes e didatizantes - são automaticamente excluídas." (op. cit., 2012, p. 25).

Para atender aos critérios qualidade do texto, adequação temática e projeto gráfico são avaliados os seguintes pontos: $1^{\circ}$ as condições de leitura, verifica a qualidade da impressão, se o espaçamento entre as linhas são adequados e o tipo de fonte utilizada; $2^{\circ}$ a qualidade da interação com o leitor, consiste em constatar se a obra apresenta questões referentes à diversidade em contextos sociais, culturais e históricos e se amplia a expectativa e perspectiva juvenis a partir da produção. E também se há uma possibilidade de incitar novas leituras; $3^{\circ}$ a qualidade textual, se há coesão, coerência e consistência e se há exploração de recursos linguísticos e expressivos; $4^{\circ}$ projeto gráfico, avaliado em relação ao formato, tamanho, capa, contracapa e em obras 
que há a relação texto-imagem, verifica-se a relação e a qualidade de interação quando há.

Abaixo temos uma tabela com os dados referentes aos números de livros inscritos pelas editoras e a quantidade de selecionados.

\begin{tabular}{|l|l|l|l|l|l|l|l|}
\hline & 2006 & 2008 & 2009 & 2010 & 2011 & 2012 & Total \\
\hline Livros Inscritos & 1.718 & 1.735 & 2.085 & 2.514 & 1.612 & 2.303 & $\mathbf{1 1 . 9 6 7}$ \\
\hline Livros Selecionados & 225 & 153 & 593 & 250 & 300 & 250 & $\mathbf{1 . 7 7 1}$ \\
\hline
\end{tabular}

Tabela 1- Números referentes à aquisição de obras entre 2006 e $2012^{4}$

A obra de Paiva (2012) não apresenta dados referentes às editoras, entretanto acreditamos ser um número baixo devido ao número de obras selecionadas e por ter editoras que podem participar com a inscrição de diferentes selos 5 . Isso ocorre porque há um limite de livros $^{6}$ que cada editora pode inscrever, desta forma, editoras com pequeno acervo completam o limite ou em muitos casos faltam obras, enquanto que para as grandes editoras é insuficiente. Assim para poder inscrever mais obras, a inscrição ocorre por selos, o que acarreta numa vantagem na "disputa", fazendo com que se concentre a grande parcela do acervo do programa em poucas editoras, na maioria dos casos de grandes editoras com diferentes selos.

A seguir temos os dados referentes à compra e a distribuição das obras do PNBE de 2006 a 2012.

\begin{tabular}{|c|c|c|c|c|}
\hline Ano & $\begin{array}{c}\text { Alunos } \\
\text { Beneficiados }\end{array}$ & $\begin{array}{c}\text { Escolas } \\
\text { Atendidas }\end{array}$ & Quantidade de Livros & Valor \\
\hline 2006 & 13.504 .906 & 46.700 & 7.233 .075 & $\mathrm{R} \$ 46.509 .183,56$ \\
\hline $2008^{7}$ & 29.284 .279 & 229.889 & 8.601 .932 & $\mathrm{R} \$ 65.283 .759,50$ \\
\hline 2009 & 20.189 .550 & 66.935 & 10.389 .271 & $\mathrm{R} \$ 74.447 .584,30$ \\
\hline
\end{tabular}

4 Dados extraídos de PAIVA, Aparecida (org). Literatura Fora da Caixa: O PNBE na escola Distribuição, Circulação e Leitura. São Paulo: Editora Unesp, 2012, p. 26.

${ }^{5}$ Uma editora pode ter vários selos, isto é, ela cria uma "marca" dentro de sua própria empresa que, em geral, publica obras de determinado assunto ou para determinado público. Ex. Editora: Companhia das Letras; Selos: Companhia das Letrinhas, Quadrinhos na Companhia etc.

${ }^{6}$ Cada editor pode inscrever 15 obras.

${ }^{7}$ Não há dados referentes a 2007, pois até 2006 a nomenclatura era referente ao ano de aquisição e passou a ser de distribuição. Assim o ano de 2008 é da distribuição e a aquisição foi feita em 2007, sendo desta forma até hoje.

Olh@res, Guarulhos, v. 2, n. 1, p. 441-459. Maio, 2014. 


\begin{tabular}{|c|c|c|c|c|}
\hline 2010 & 24.723 .464 & 248.817 & 10.660 .701 & $\mathrm{R} \$ 48.766 .695,45$ \\
\hline 2011 & 20.092 .968 & 69.003 & 5.585 .414 & $\mathrm{R} \$ 70.812 .088,00$ \\
\hline 2012 & 22.305 .401 & 240.201 & 10.485 .353 & $\mathrm{R} \$ 81.437 .946,11$ \\
\hline Total & $\mathbf{1 3 0 . 1 0 0 . 5 5 8}$ & $\mathbf{9 0 1 . 5 4 5}$ & $\mathbf{5 2 . 9 5 5 . 7 4 6}$ & $\mathbf{R} \$ \mathbf{3 8 7 . 2 5 7 . 2 5 7 , 9 2}$ \\
\hline
\end{tabular}

Tabela 2 - Números relativos à compra e distribuição do PNBE entre 2006 e $2012^{8}$

\section{Identificação das HQ's}

Ao longo do período ${ }^{9}$ de seleção de histórias em quadrinhos foram ao todo 81 livros, sendo 22 adaptações literárias. A seguir, temos uma tabela que ilustra tais dados, divididos pelos anos de seleção.

\begin{tabular}{|c|c|c|}
\hline Ano & Obras Adquiridas & Adaptações Literárias \\
\hline 2006 & 11 & 3 \\
\hline 2008 & 7 & 1 \\
\hline 2009 & 21 & 5 \\
\hline 2010 & 9 & 2 \\
\hline 2011 & 26 & 8 \\
\hline 2012 & 7 & 3 \\
\hline Total & $\mathbf{8 1}$ & $\mathbf{2 2}$ \\
\hline
\end{tabular}

Tabela 3 - Quantidade de obras adquiridas e adaptações literárias

A distribuição de todas as HQ's por níveis foi feita seguinte forma:

Educação Infantil, 1 obra; Ensino Fundamental I, 13 obras; Ensino Fundamental II, 41 obras; Ensino Médio, 17 obras; Educação de Jovens e Adultos, 9 obras. Na divisão das adaptações não há obras destinadas à Educação Infantil, para o Ensino Fundamental I, 2 obras; 10 obras para o Ensino Fundamental II; 6 e 4 obras para Ensino Médio e Educação de Jovens e Adultos, respectivamente.

As adaptações selecionadas foram:

\begin{tabular}{|l|l|l|l|}
\hline Título & Editora & Nível & Ano \\
\hline A metamorfose & Conrad & E. F. II & 2006 \\
\hline Dom Quixote em quadrinhos & Peirópolis & E. F. II & 2006 \\
\hline Contos em quadros & Musa & E. F. II & 2006 \\
\hline
\end{tabular}

\footnotetext{
${ }^{8}$ Dados extraídos de PAIVA, Aparecida (org). Literatura Fora da Caixa: O PNBE na escola Distribuição, Circulação e Leitura. São Paulo: Editora Unesp, 2012, p. 21.

${ }^{9}$ De acordo com Vergueiro e Ramos (2009), desde 2006 são selecionados quadrinhos para o PNBE. Contabilizamos até o ano de 2012.
}

Olh@res, Guarulhos, v. 2, n. 1, p. 441-459. Maio, 2014. 


\begin{tabular}{|l|l|l|l|}
\hline Os Lusíadas em quadrinhos & Peirópolis & E. F. I & 2008 \\
\hline O Alienista de Machado de Assis & Agir & E. M. & 2009 \\
\hline Domínio Público: Literatura em quadrinhos & DCL & E. M. & 2009 \\
\hline Oliver Twist & Companhia Editora Nacional & E. F. II & 2009 \\
\hline O beijo no asfalto & Nova Fronteira & E. F. II & 2009 \\
\hline O triste fim de Policarpo Quaresma & Companhia Editora Nacional & E. F. II & 2009 \\
\hline O pequeno príncipe & Agir & EJA & 2010 \\
\hline Memórias de um sargento de milícias & Companhia Editora Nacional & EJA & 2010 \\
\hline O Guarani em quadrinhos & Cortez & E. M. & 2011 \\
\hline O Cortiço & Ática & E. M. & 2011 \\
\hline Robison Crusoé & Salamandra & E. M. & 2011 \\
\hline Frankenstein & Salamandra & E. M. & 2011 \\
\hline O curioso caso de Benjamin Button & Ediouro & E. F. II & 2011 \\
\hline O Guarani & Ática & E. F. II & 2011 \\
\hline Memórias de um sargento de milícias & Ática & E. F. II & 2011 \\
\hline O triste fim de Policarpo Quaresma & Ática & E. F. II & 2011 \\
\hline Turma da Mônica: Romeu e Julieta & Panini & E. F. I & 2012 \\
\hline Drácula & Companhia Editora Nacional & EJA & 2012 \\
\hline Frankenstein & Companhia Editora Nacional & EJA & 2012 \\
\hline
\end{tabular}

Tabela 4 - Obras de adaptações em quadrinhos selecionadas pelo programa

\section{Os problemas e as soluções}

Para Vergueiro e Ramos (2009), ao selecionar essas obras haveria o pressuposto de que elas seriam facilitadoras de leitura e pré-leitura da obra original. Sim, a partir do conceito de adaptar ${ }^{10}$ esses quadrinhos podem ser entendidos como facilitadores do original, visto que há uma releitura de texto e uma adequação a uma nova linguagem, desta forma lidamos com duas obras, apesar de ambas terem o mesmo enredo. Também podendo ter uma aproximação maior com determinado público, no caso, por exemplo, dos quadrinhos é claro que haverá uma aproximação com leitores do gênero, independente de idade.

\footnotetext{
10 Böhm (2004) define que adaptar é adequar algo. Neste caso considera-se a linguagem da obra original, a linguagem na qual será adaptada, o público alvo e o suporte, gerando assim um novo produto.

Olh@res, Guarulhos, v. 2, n. 1, p. 441-459. Maio, 2014.
} 


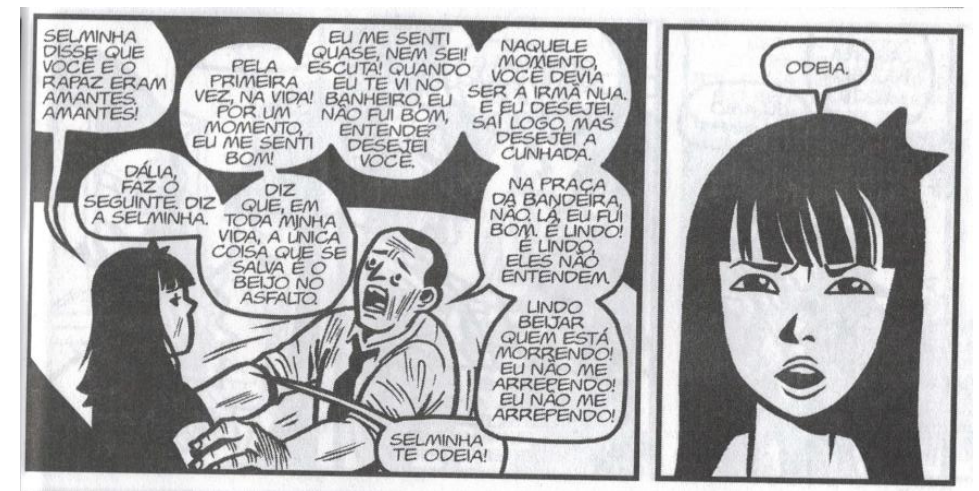

Figura 1 - Adaptação de O beijo no Afasto ilustra o conceito de Böhm (2004), que visa adaptar a linguagem. BRANCO, Arnaldo; GÓES, Gabriel. O beijo no asfalto. São Paulo: Nova Fronteira, 2007. p. 63

A imagem acima é da adaptação $O$ beijo no asfalto. A obra original de Nelson Rodrigues foi produzida para teatro, desta forma o quadrinista precisa analisar a linguagem do original para adequar à nova, neste caso os quadrinhos. As falas que são construídas a partir de um travessão devem estar dentro de um balão de fala, característica própria da HQ. Outro ponto que deve ser ressaltado é o suporte, pois é a partir dele que são feitas novas adequações e o que pode alterar o gênero.

No segundo quadrinho vemos que há uma focalização na personagem, um recurso dos quadrinhos, chamado primeiro plano, que segundo Ramos (2009) foca nas expressões faciais, o que em uma encenação teatral não seria possível, por isso o suporte ${ }^{11}$ também deve ser considerado. E principalmente o público, porque pode ser distinto ou o mesmo, aquele que vê a adaptação no teatro pode ser ou não o mesmo que lê a adaptação em quadrinhos ou a obra original.

As releituras são comuns, estão no cinema, no teatro, nas novelas, nas animações, nas contações orais etc. E o telespectador do cinema, por exemplo, pode assistir ao filme sem ter lido a obra original e irá compreender, mas não por completo como a do telespectador leitor, pois lhe faltarão informações prévias, contudo nada o impede de ler, nem o obriga, porque são textos distintos ${ }^{12}$.

\footnotetext{
${ }^{11}$ De acordo com Marcuschi (2008), suporte é o locus físico ou virtual com formato específico que serve de base ou ambiente de fixação do gênero materializado como texto. (op. cit. p. 174)

${ }^{12}$ Hattnher (2010), o texto que é tomado como base para uma adaptação transforma-se em outros, que não podem ser considerados nem melhores nem piores, mas diferentes, desta forma, deixa-se de se ter um texto e passa-se a ter muitos textos.

Olh@res, Guarulhos, v. 2, n. 1, p. 441-459. Maio, 2014.
} 
Tal fórmula também pode acontecer com as adaptações em quadrinhos. Um aluno pode ler a HQ e interessar-se pela obra original ou buscar o quadrinho porque gostou do texto adaptado. Na verdade esse desejo deve ser despertado e entra como fundamental nesse processo o mediador, que pode e "deve" apresentar as opções de leitura.

Como professor, o mediador pode discutir a obra original em sala e pedir para que comparem com a adaptação. Ao fim de uma sessão de um filme buscar e apresentar informações sobre em que foi baseado. Qualquer forma de leitura de adaptações ajuda a compreender a obra original, mas não é uma leitura completa se a intenção é trabalhar com o texto oriundo. Então, sim as adaptações selecionadas pelo governo podem ajudar na compreensão e como incentivador à leitura original, sem nos esquecermos de que se trata de duas obras.

Uma adaptação, seja ela em quadrinhos ou não, deve ser adequada ao público ao qual é destinada, pois há níveis de conhecimento ${ }^{13}$. No caso da escola é diferente para cada série em que o aluno se encontra, assim, se houver uma adaptação de uma obra que o aluno provavelmente lerá no Ensino Médio destinada ao Ensino Fundamental I e II poderá ajudá-lo na leitura e na compreensão da obra original, tendo em vista que já terá contato com o enredo da história e suas informações serão complementadas.

O que não se pode perder é a relação com o original, como aconteceu com a obra Winnie-the-Pooh, de Alan Alexander Milne, que para muitos está associado ao filme da Disney ${ }^{14}$. Para isso é de fundamental importância que os mediadores de leitura saibam trabalhar com adaptações literárias para que os alunos procurem o

\footnotetext{
${ }^{13}$ Estabelecemos aqui uma relação com o conceito de Piaget (2003) sobre desenvolvimento intelectual por estágios. $\mathrm{O}$ pesquisador divide os estágios em: recém-nascido e o lactente; primeira infância ( 2 a 7 anos); Infância (7 a 12 anos) e Adolescência (a partir dos 12 anos). Define que em cada estágio há desenvolvimento intelectual e este é feito a partir de interações com o mundo. Para o pesquisador, todos aqueles que, do ponto de vista biológico, nasceram sem problemas são potencialmente dotados das mesmas condições para o desenvolvimento cognitivo, ainda que as condições materiais e/ou culturais possam reforçar ou reprimir em parte esse desenvolvimento. A exemplo, o documentário Babies (2010), que quatro bebês, em condições culturais e socioeconômicas diferentes, se desenvolvem no mesmo período de vida e com práticas sociais parecidas.

${ }^{14}$ A obra é de 1926 e virou adaptação em 1977.

Olh@res, Guarulhos, v. 2, n. 1, p. 441-459. Maio, 2014.
} 
original e também para que se tornem leitores de clássicos da literatura mundial. E no caso dos quadrinhos, que haja uma formação sobre sua linguagem, pois, segundo Vergueiro (2010),

\begin{abstract}
A "alfabetização" na linguagem específica dos quadrinhos é indispensável para que o aluno decodifique as múltiplas mensagens neles presentes e, também, para que o professor obtenha melhores resultados em sua utilização. (op. cit., 31)
\end{abstract}

As múltiplas mensagens que o pesquisador refere-se são as marcar linguísticas das HQ's. Para ilustrar temos um quadrinho da adaptação do conto Pai contra Mãe, de Machado de Assis. A produção faz parte do livro Contos em quadros, que conta com três adaptações de contos brasileiros, seguidos de seu texto original.

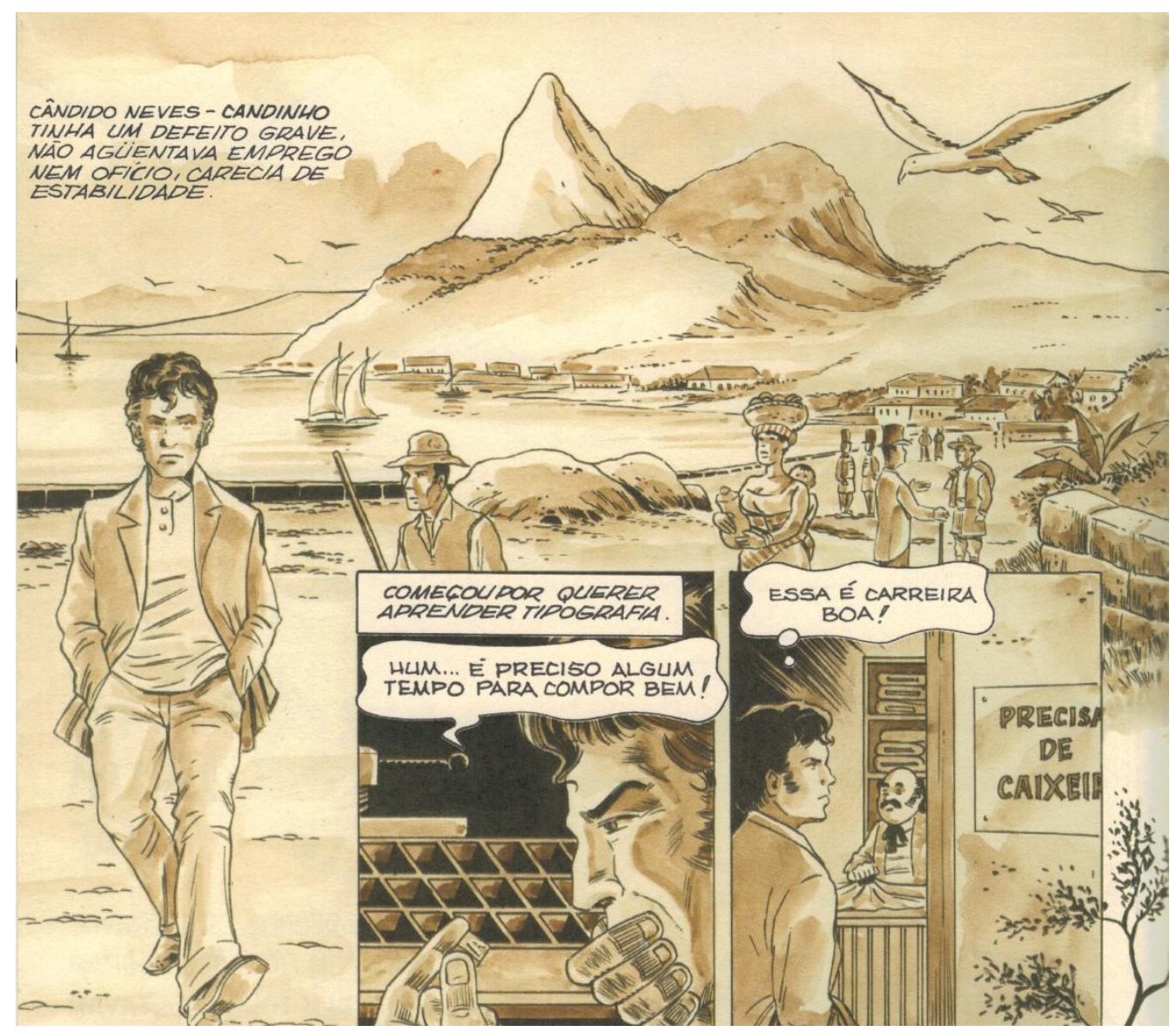

Figura 2 - Contos em Quadros. Adaptação de Pai contra Mãe ilustra o conceito de adaptar. CAVALCANTE, Djalma; LIMA, Celia. Contos em quadros. São Paulo: Musa, 2002. p. 8

A imagem acima é do primeiro quadrinho da adaptação, ela ilustra o que Vergueiro (2010) defende como múltiplas linguagens. O quadrinho praticamente não altera a forma da linguagem escrita do Olh@res, Guarulhos, v. 2, n. 1, p. 441-459. Maio, 2014. 
texto original, mas o que é importante observar é a manutenção do que é essencial para a construção do texto com a imagem, pois se houvesse mantido o texto na íntegra seria redundante, e o uso dos balões é outra marca, porque sua construção é diferente para o balão de fala e de pensamento.

A seguir temos o trecho do texto original para elucidar, reafirmando a colocação do pesquisador em relação à alfabetização na linguagem dos quadrinhos.

Cândido Neves, - em família, Candinho, - é a pessoa a quem se liga a história de uma fuga, cedeu à pobreza quando aderiu o ofício de pegar escravos fugidos. Tinha um defeito grave esse homem, não aguentava emprego nem ofício, carecia de estabilidade; é o que ele chamava caiporismo. Começou por querer aprender tipografia, mas viu cedo que era preciso algum tempo para compor bem, e ainda assim talvez não ganhasse o bastante; foi o que ele disse a si mesmo. O comércio chamou-lhe a atenção, era carreira boa. Com algum esforço entrou de caixeiro para um armarinho. A obrigação, porém de atender e servir a todos feria-o na corda do orgulho, e ao cabo de cinco ou seis semanas estava na rua por sua vontade. (ASSIS: 2002, p. 21)

Todavia, a formação dos mediadores para trabalhar com as obras do PNBE e os obstáculos de disponibilização são uns dos problemas que o programa precisa enfrentar. Dados evidenciados por Paiva (2012), ao afirmar que alunos e professores estão à margem das obras disponibilizadas, por falta de políticas que avancem no processo de formação de leitores. Para essa formação é essencial o mediador, porque de acordo com Vygotsky apud Oliveira (1997), a intervenção pedagógica é essencial para a promoção do desenvolvimento em cada indivíduo, pois este não percorreria o caminho de desenvolvimento sem ter experiências de aprendizado resultados pela experiência de outros indivíduos em sua vida e para se desenvolver adequadamente em sua cultura.

Também há problemas nas escolhas dessas adaptações. Entendemos como problema a seleção de quadrinhos destinados ao EJA, pois ao falarmos deste grau de ensino não estão definidas para quais séries serão destinadas, tendo em vista que o aluno do $1^{\circ}$ ano do Ensino Fundamental, não é o mesmo leitor do que está no $1^{\circ}$ ano do Ensino Médio e não há qualquer distinção nos editais. E pode ser uma questão que esteja nas inscrições das obras, etapa que as editoras cadastram os

Olh@res, Guarulhos, v. 2, n. 1, p. 441-459. Maio, 2014. 
quadrinhos que passarão pelo processo de seleção, sendo que cada editora tem um limite de obras, por categoria. Todavia, não se eximi a "culpa" dos editais e os selecionadores, porque não estão claros os critérios para este nível, que poderia ser feito como a Educação Básica que distingue os anos iniciais e os finais do Ensino Fundamental.

3.2.4. Categoria 4: para escolas que atendem alunos da educação de jovens e adultos - etapas do ensino fundamental e do ensino médio:

3.2.4.1. Textos em verso - poema, cordel, provérbios, ditos populares;

3.2.4.2. Textos em prosa - romance, novela, conto, crônica, teatro, biografia, diário, relato de experiência, texto de tradição popular;

3.2.4.3. Livros de imagens e livros de histórias em quadrinhos, dentre os quais se incluem obras clássicas da literatura universal, artisticamente adaptadas ao público de educação de jovens e adultos (ensino fundamental e médio). (BRASIL, 2012, p. 2)

Outro problema é a manutenção do texto original, porque pode ser visto como um facilitador de leitura e ao manter pode não exercer tal função e até mesmo não ser adequado ao grau escolar. É o que acontece, em nosso entender, com a adaptação Os Lusíadas em quadrinhos, porque foi destinada ao Ensino Fundamental I, o que pode resultar em uma dificuldade de trabalho em sala de aula com alunos deste nível, já que estão em fase de alfabetização e a linguagem escrita é complexa até para adultos.

A seguir temos a imagem do quadrinho, seguido do trecho do canto (Canto III, estrofes 119-121) em que o quadrinho se baseou, que ilustram essa manutenção textual. O que julgamos poder gerar problemas em sala de aula. 


\section{Znếs de Clastro}
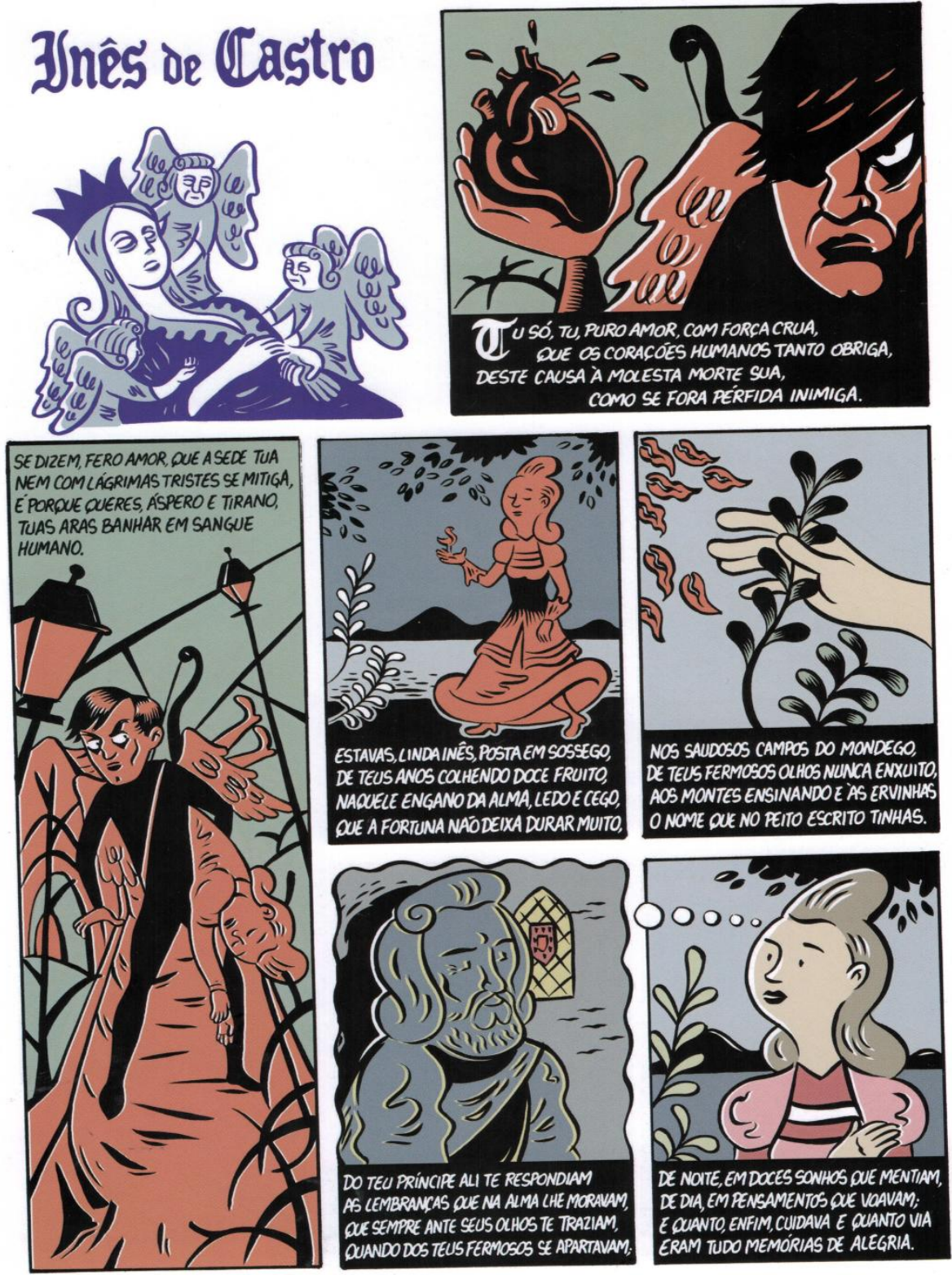

Figura 3 - O trecho ilustra a manutenção do texto original no quadrinho. NESTI, Fido. Os Lusíadas em quadrinhos. São Paulo: Peirópolis, 2006. p. 9

Tu só. Tu, puro Amor, com força crua, Que os corações humanos tanto obriga, Deste causa à molesta morte sua,

Como se fora pérfida inimiga.

Se dizem, fero Amor, que a sede tua

Nem com lágrimas tristes se mitiga,

É porque e queres, áspero e tirano,

Tuas aras banhar em sangue humano.

Estavas, linda Inês, posta em sossego,

De teus anos colhendo doce fruito,

Naquele engano da alma, ledo e cedo,

Que a Fortuna não deixa durar muito,

Nos saudosos campos do Mondego,

De teus fermosos olhos nunca enxuito,

Aos montes ensinado e às ervinhas

Olh@res, Guarulhos, v. 2, n. 1, p. 441-459. Maio, 2014. 
O nome que no peito escrito tinhas.

Do teu Príncipe ali te respondiam As lembranças que na alma lhe moravam, Que sempre ante seus olhos te traziam, Quando dos teus fermosos se apartavam; Da noite, em doces sonhos que mentiam. De dia, em pensamentos que voavam. E quanto, enfim, cuidava e quanto via Eram tudo memórias de alegria.

(CAMÕES: 1999, p. 96-97)

\title{
Considerações Finais
}

Verificamos que apesar de, segundo Vergueiro e Ramos (2009), haver uma preferência por adaptações em quadrinhos o número de outros gêneros prevalece (22 obras de adaptações em quadrinhos e 59 de outros gêneros). E há o entendimento de que esses quadrinhos podem facilitar a leitura para as crianças por conter imagens, tendo em vista as declarações de representantes governamentais.

\begin{abstract}
Os quadrinhos, do ponto de vista do governo, são vistos como uma ferramenta mais atraente para estimular a leitura. "O papel apelo visual, a figura, é algo que atrai demais a criança, é uma forma de ela se interessar para a leitura por um outro formato", diz Cecília Correa Sampaio, coordenadora substituta do departamento de seleção de obras do PNBE. (RAMOS, 2012, p. 225)
\end{abstract}

Tendo claro que pode haver tal interesse é curioso ver os dados relativos a compras destinadas ao EJA, pois o número é crescente e não está claro qual é o leitor deste grau de ensino. São jovens e adultos, mas com qual nível de ensino? Ainda sim, o número de adaptações destinadas ao Ensino Fundamental II é o maior, são 10 livros e evidencia que há o entendimento que para crianças é mais atraente e que ao lidar com o quadrinho nessa fase pode fazer com que posteriormente procure a obra original.

De fato, qualquer adequação literária pode ser atrativa e há a possibilidade de procura para o original por conta própria, mas seria ideal, pensando em formação de leitores, que haja um trabalho de mediação e para isso os profissionais que exercem tal função precisam estar preparados para lidar com o acervo do PNBE.

Olh@res, Guarulhos, v. 2, n. 1, p. 441-459. Maio, 2014. 
Contudo, ainda há problemas na distribuição que precisam ser resolvidos, como foi apontado por Montuani (2012), em que há obras que chegam às escolas, mas não saíram das caixas. E não é muito difícil constatar tais problemas de disponibilidade em escolas públicas $^{15}$, porque muitas não possuem uma estrutura física adequada para as bibliotecas, isso quando abrem.

Também é necessário que fique claro alguns critérios de seleção, para que editoras não submetam quadrinhos que não são "adequados" aos níveis e para ser justa com as pequenas editoras e com obras de qualidade, tanto em imagem quanto da apropriação do texto original. Apesar de apresentar alguns problemas, não podemos deixar de evidenciar a importância do programa, como bem fez Paiva (2012), visto que há uma iniciativa de formar novos leitores, fazendo com que as obras possam chegar a eles. E a inclusão das HQ's mostra que se está rompendo uma barreira de preconceitos sobre o gênero, pois por um período foram proibidas nas escolas ${ }^{16}$ e é vista socialmente como um passatempo e não como forma de leitura.

E o uso desses quadrinhos em sala de aula é aqui trabalhado como suposição do que pode ser feito, evidenciando os problemas do programa, que interferem nesse trabalho e quais seriam possíveis soluções de uso, mas são necessárias pesquisas para constatar se as questões aqui levantadas são de fato essenciais para o uso em sala.

\footnotetext{
${ }^{15}$ Durante minha licenciatura na Universidade Federal de São Paulo pude constatar tal realidade, que também pode ser verificada no relato de experiência de Caretta e Nacaguma (2013).

${ }^{16}$ De acordo com Gonçalo Júnior (2004), nas décadas de 1950/1960 começou-se a restringir a leitura de HQ`s, pois a partir de uma pesquisa realizada nos Estados Unidos, pelo psiquiatra Frederic Wertham, que afirmava que o gênero fazia com os seus leitores se tornassem marginais e tivessem preguiça mental, por causa disso pais e escolas não autorizavam a leitura.
}

Olh@ res, Guarulhos, v. 2, n. 1, p. 441-459. Maio, 2014. 
Referências

ASSIS, Machado. Pai Contra Mãe. In: CAVALCANTE, Djalma; LIMA, Celia. Contos em quadros. São Paulo: Musa, 2002. p. 20-27

BA, Gabriel; MOOM, Fábio. O alienista de Machado de Assis. São Paulo: Agir, 2007.

BABIES. Direção: Thomas Balmes. França, Paris: Focus Features, 2010 (97 min)

BÖHM, Gabriela. Peter Pan para crianças brasileiras: a adaptação de Monteiro Lobato para a obra de James Barrie. In: CECCANTINI, João Luis (org.). Leitura e literatura infanto-juvenil. São Paulo: Cultura Acadêmica Editora, 2004. p.58-71.

BRANCO, Arnaldo; GÓES, Gabriel. O beijo no asfalto. São Paulo: Nova Fronteira, 2007.

BRASIL. Ministério da Educação. Edital de convocação para o processo de inscrição e avaliação de obras de literatura para o Programa Nacional Biblioteca da Escola PNBE 2012. Brasília: 2011.

CAMÕES, Luis Vaz de. Os Lusíadas. São Paulo. Editora Klick, 1999.

CARETTA, Álvaro Antonio; NACAGUMA, Simone. Relato de experiência: a parceria escola-universidade no protagonismo da formação docente. In: Olh@res. $\mathrm{N}^{\circ}$ 1; Maio, 2013. p. 436-454

CAVALCANTE, Djalma (org.); LIMA, Celia (adapt.); SILVA, José Rodrigues (ilustr.). Contos em quadros. São Paulo: Musa, 2002.

CAVAlCANTI, Lailson de Holanda. O triste fim de Policarpo Quaresma. São Paulo: Companhia Editora Nacional, 2008.

CAVALCANTI, Lailson de Holanda. Memórias de um sargento de milícias. São Paulo: Companhia Editora Nacional, 2008.

Dickens, Charles. Oliver Twist. São Paulo: Companhia Editora Nacional, 2008.

FERNANDES, Célia Regina Delácio. Leitura, Literatura Infanto-Juvenil e Educação. Londrina: EDUEL, 2007.

FIUZA, Enzo. O curioso caso de Benjamin Button. São Paulo: Ática, 2008.

GARLHADO, Caco. Dom Quixote em quadrinhos. São Paulo: Peirópolis, 2005.

GAUTHIER, Christoph. Robison Crusoé. Trad. Luciano Vieira Machado. São Paulo: Salamandra, 2009.

GÊ, Luis; JAF, Ivan. O Guarani. São Paulo: Ática, 2009.

GONÇALO JÚNIOR. A Guerra dos Gibis: A formação do Mercado Editorial Brasileiro e a Censura aos Quadrinhos, 1933-1964. São Paulo: Companhia das Letras, 2004.

HATTNHER, Alvaro Luiz. Quem mexeu no meu texto? Observações sobre literatura e sua adaptação para outros suportes textuais. In: Revista Brasileira de Literatura Comparada. $\mathrm{N}^{\circ} 16,2010$. p. $145-155$

JAF, Ivan. O cortiço. São Paulo: Ática, 2009.

JAF, Ivan; ROSA, Rodrigo. Memórias de um sargento de milícias. São Paulo: Ática, 2010.

Olh@res, Guarulhos, v. 2, n. 1, p. 441-459. Maio, 2014. 
KALMAN, Judith. El estúdio de la comunidad como un espacio para leer y escribir. In: Revista Brasileira de Educação. No 26; Maio/jun/jul/ago, 2004. p. 05-28.

KUPER, Peter. A metamorfose. São Paulo: Conrad, 2004

LIN, João; MASCARO. Domínio Público: literatura em quadrinhos. São Paulo: DCL 2008.

LOBO, César. O triste fim de Policarpo Quaresma. São Paulo: Ática, 2010.

MACDONALD, Fiona. Drácula. São Paulo: Companhia Editora Nacional, 2010.

Frankenstein. São Paulo: Companhia Editora Nacional, 2010.

MARCUSCHI, Luiz Antônio. Produção textual, análise de gêneros e compreensão. São Paulo: Parábola Editorial, 2008.

MEC (Ministério da Educação). Portal do MEC que contém todas as informações referentes ao PNBE (Programa Nacional Biblioteca da Escola) $<$ http://portal.mec.gov.br/index.php?option=com_content\&view=article\&id=13698\&Ite mid=986> Acesso em 16 de Ago. 2013.

MILNE, Alan Alexander. Winnie-the-Pooh. New York: Penguin II, 2006.

MONTUANI, Daniela Freitas Brito. Acervos de Literatura Chegam na Escola? In: PAIVA, Aparecida (org). Literatura Fora da Caixa: O PNBE na escola Distribuição, Circulação e Leitura. São Paulo: Editora Unesp, 2012, p.77-110.

MOUSSE, Marion. Frankenstein. Trad. Luciano Vieira Machado. São Paulo: Salamandra, 2009.

NESTI, Fido. Os Lusíadas em quadrinhos. São Paulo: Peirópolis, 2006.

OLIVEIRA, Marta Kohl. Desenvolvimento e Aprendizado. In: Vygotsky Aprendizado e Desenvolvimento: um processo-histórico. $4^{\text {a }}$ ed. São Paulo: Scipione, 1997. p. 55-79.

PAIVA, Aparecida. Políticas Públicas de Leitura: Pesquisas em Rede. In: PAIVA, Aparecida (org). Literatura Fora da Caixa: O PNBE na escola - Distribuição, Circulação e Leitura. São Paulo: Editora Unesp, 2012, p.13-33.

PIAGET, Jean. Seis estudos de psicologia. $24^{\text {a }}$ ed. Rio de Janeiro: Forense Universitária, 2003.

RAMOS, Paulo. A revolução do gibi: a nova cara dos quadrinhos no Brasil. São Paulo: Dervir, 2012.

A leitura dos quadrinhos. São Paulo: Contexto, 2009.

SFAR, JOANN. O pequeno príncipe em quadrinhos. São Paulo: Agir, 2008.

SOUSA, Maurício de. Turma da Mônica: Romeu e Julieta. São Paulo: Panini, 2009.

THE Many Adventures of Winnie the Pooh. Direção: Wolfgang Reitherman e John Lounsbery. Estados Unidos da América: Walt Disney Pictures, 1977.

VERGUEIRO, Waldomiro. A linguagem dos quadrinhos: uma "alfabetização" necessária. In: RAMA, Ângela; VERGUEIRO, Waldomiro. Como usar as histórias em quadrinhos na sala de aula. São Paulo: Contexto, 2010. p. 31-64 
VERGUEIRO, Waldomiro e RAMOS, Paulo. Os quadrinhos (oficialmente) na escola: dos PCN ao PNBE. In:

Paulo: Contexto, 2009. p. 9-42

Quadrinhos na Educação: da rejeição à prática. São

VETILLO. Walter. O guarani: em quadrinhos. São Paulo: Cortez, 2010. 